\title{
Immigration could ease climate-change impact
}

\section{A modest proposal to allow the big gas-emitters to take their share of responsibility.}

Sir - The recent UN World Conference on Disaster Reduction in Kobe, Japan, was dominated by discussion of the Indian Ocean tsunami ("Solo efforts hamper tsunami warning system" Nature 433, 343; 2005). However, we must not forget the extreme vulnerability of small islands and low-lying coastal areas to sea-level rise caused by climate change.

The accumulation of greenhouse gases in the atmosphere during the past few hundred years is likely to result in a sealevel rise of up to half a metre, possibly more, by 2050 (R. J. Nicholls \& J. A. Lowe, Glob. Environ. Change, in the press). Many of the affected countries do not have the resources to adopt protective measures such as sea walls and embankments, nor can they afford insurance. By the end of the century, millions are likely to have been driven from their homes by sea-level rise.

One of the ironies of climate change is that, although wealthy countries are responsible for most of the accumulated greenhouse gases in the atmosphere, they will probably face less damage than poor countries. As climate negotiations 'beyond Kyoto' take shape, it is time to consider a framework wherein people living in areas likely to be rendered uninhabitable by climate change would have the early option of migrating elsewhere - specifically to those countries that are largely responsible.

The number of vulnerable 'climatechange exiles' received by a host country would be in approximate proportion to that country's cumulative greenhouse-gas emissions. Estimates suggest that roughly 50 million to 200 million people will be displaced by the 2080s, owing to the direct impacts of climate change under a plausible range of emissions scenarios (R. J. Nicholls Glob. Environ. Change 14, 69-86; 2004). Assuming that all these climate-change exiles are absorbed by the top ten 'emitter' countries, new annual immigrants would range from a few thousand for the Czech Republic to about three-quarters of a million for the United States.

Once the basic principle (which is consistent with Articles 1 and 4.8 of the United Nations Framework Convention on Climate Change) is accepted, there will be several ways to determine who should be considered for immigration benefits, which countries should bear the costs of immigration, and what institutional and political mechanisms are needed in order to minimize the risks of a massive refugee crisis as climate impacts become more severe.

Figuring out an international strategy to address the needs of these climatechange exiles will be easier now than later. Sujatha Byravan*, Sudhir Chella Rajan $\dagger$ *Council for Responsible Genetics, 5 Upland Road, Cambridge, Massachusetts 02140, USA $\dagger$ Tellus Institute, 11 Arlington Street, Boston, Massachusetts 02116, USA

\section{Consumer law is used to attack climate findings}

Sir - Your News story "Salt sellers challenge US health agency using dataquality act" (Nature 433, 671; 2005), suggests that a lawsuit filed by the Salt Institute represents "the first time that a petitioner has actually sued under the Data Quality Act". This is not the case, although the ruling that the Salt Institute is appealing was the first verdict given in a case brought under the federal Data Quality Act.

In August 2003 a conservative advocacy group, the Competitive Enterprise Institute, filed a suit claiming violations of the act against President George Bush and John Marburger, director of the White House Office of Science and Technology Policy (OSTP). The most important claim was that reports by the US National Assessment of the potential consequences of climate change (USNA) used results from two different global climate models to construct scenarios of future climate (see National Assessment Synthesis Team, Climate Change Impacts on the United States, Cambridge Univ. Press, Cambridge, 2000) — which therefore violated the act because one of the two scenarios had to be in error.

In November 2003, just as the Department of Justice was preparing to file its response, the parties accepted a ruling of "dismissal with prejudice", meaning that the lawsuit could not be refiled. Although the Department of Justice did not release its brief, it had apparently made a strong argument against the absurd notion that projections of the future must be proven accurate in advance.

The OSTP nonetheless ordered that a notice be added to USNA web pages, indicating that the reports "were not subjected to OSTP's Information Quality Act Guidelines". This implies that the USNA report was not properly reviewed and would not meet the OSTP guidelines. This is misleading at best, as the report was subjected to a four-stage review that was more comprehensive than called for by the act. In addition, the OSTP guidelines did not exist or apply at the time that the USNA was released.

Attempts by the USNA's lead authors and contributors (including myself) to get this notice removed or modified have failed, leaving in place an unfair criticism of the assessment's widely accepted findings. Michael C. MacCracken

Climate Institute, 1785 Massachusetts Avenue NW, Washington DC 20036, USA

\section{That chemist pose is a classic because we do it}

Sir - I note with some surprise that Philip Ball, in his Science in Culture article "What's in the flask?" (Nature 433, 17; 2005), says that gazing into a flask held aloft — as in the stereotypical image -

"is not what real chemists spend their time doing". As a synthetic organic chemist, I would like to point out that this is exactly what real chemists do.

My research group regularly observes the initiation of crystallization or precipitation in this fashion. Magnification through the curved walls of the flask, with the brightly lit background of the ceiling lighting, lets one see the changes in the morphology of small particles as they form (often at the liquid surface), while trying to avoid solutes crashing out of solution unselectively.

As chemistry is so often the glue connecting biology, physics and medicine in this interdisciplinary age, we can only hope that more people will discover what chemists actually do.

Piers R. J. Gaffney

Department of Chemistry, Imperial College, South Kensington Campus,

Exhibition Road, London SW7 2AZ, UK

Erratum In David M. Wilkinson's Correspondence letter "Brown knew particles were smaller than pollen" (Nature 434, 137; 2005), the sentence "The microscopic particles involved in the characteristic jiggling dance Brown described were much smaller clay particles" should not have contained the word "clay", which was added in error during the editing process. The particles Brown saw were inside the pollen grains.

\section{correspondence}

Contributions to Correspondence may be submitted to corres@nature.com. They should be no longer than 500 words, and ideally shorter. 